
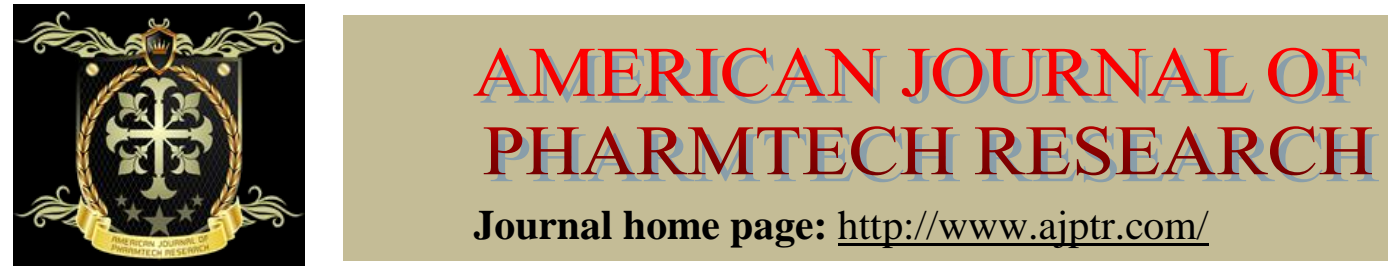

Journal home page: http://www.ajptr.com/

\title{
Pharmaceutical \& Cosmetical Application of Keratin Protein Obtaining from Biowaste- A Review
}

Gayatri G. Varma*, Pranali R. Sonawane, Mrs. Shubhangi S. Bhide Ideal College of Pharmacy \& Research Institute Bhal, Kalyan, Thane, Maharashtra, India.

\section{ABSTRACT}

Keratin is a fibrous structural protein and major component of hair, horns, claws, hooves, feather, wool, hoof and outer layer of skin. These keratinous materials are formed by cells filled with keratin and are considered 'dead tissue'. Keratin acts both as an external protective protein \& internal structural protein in the cortex. It is insoluble in water and organic solvents. Keratin can be derived from the human and animal sources by the advancement in extraction, purification and characterization process. It consists of highly repetitive amino acid sequences which result in formation of various homogeneous secondary structures. Keratin has been processed in oxidized and reduced forms in term of keratose and kerateine which shows strong mucoadhesive properties in drug delivery systems .It can also be processed as keratin hydrolysate by using acid, alkali and enzyme. Especially for hair care products, skin treatment and harsh products such as detergents, shampoos, conditioners etc. As it does not contain any harmful effect, it can be used to produce variety of cosmetics and pharmaceutical products. In addition, extracted keratins are capable of forming self-assembled structures that regulate cellular recognition and behavior. These qualities of keratin led to the development of biomaterials with applications in wound healing, drug delivery, target release action, tissue engineering, trauma and medical devices. This review discusses the natural sources of keratin and their derivatives and application of keratin biomaterials in pharmaceutics and cosmetics.

Keywords: Keratin, keratin hydrolysate, Phytokeratin, Biomaterials, Drug delivery, keratin film, Nanoparticles, cosmetics. 


\section{INTRODUCTION}

Several efforts have been made for the development of green materials. Yet there is much left to replace chemically synthesized materials with biodegradable and environmental friendly biomaterial in pharmaceutical and other industries. A ubiquitous biological materials, keratin is cysteine rich protein widespread in biological tissues, being a major functional component. The solubility and structural integrity of keratin including biocompatibility, biodegradability, bioactivity, non-toxicity, low cost \& easy to process makes it an ideal polymer. ${ }^{[1]}$

Keratin can be classified in to Alpha, Beta and Gamma keratin. Alpha keratin is found in hair fibers, Beta in hair cuticle, which is protective in function, and Gamma keratin is present in hair follicle. It contains higher sulphur content. ${ }^{[23]}$ Its disulfide and covalent bonds are mainly responsible for its chemical and mechanical resistance. ${ }^{[2]}$ Animal-derived keratins seem compatible with human biological system if it is carefully extracted from the source. It is used as platform technology to make biomaterials for biomedical applications. ${ }^{[3]}$ The ability of extracted keratin to self-assemble in to three dimensional porous structures has led to its development as scaffolds for biomedical applications.

\section{BIOLOGICAL SOURCES OF KERATIN}

Keratin is found in a human skin, hair, nails. It also found in reptiles, birds, amphibians and other mammals ${ }^{[4]}$ sometime including the hooves of animals.
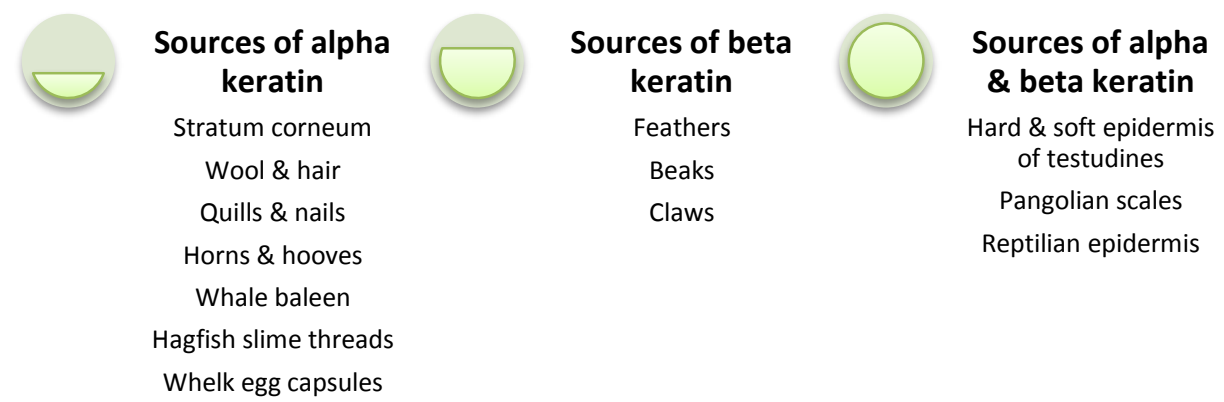

It also found in the spider web and silk of silkworm. ${ }^{[5]}$ Chicken feathers consist of approximately $90 \%$ of total protein and it is the ideal material for obtaining keratin from waste biomass of poultry industries.

Phytokeratin is a composite product made by blending free amino acids from plants in the same proportions as that of found in popular human hair amino acid products. Some phytokeratins are the Hydrolyzed Soy Protein, Hydrolyzed Corn Protein and Hydrolyzed Wheat Protein responsible for the Moisturizing, Film-forming and Moisture binding effects. ${ }^{[58]}$

\section{CHEMICAL COMPOSITION}


Keratin is cysteine rich protein widespread in biological tissues being a major functional component. Cysteine is present in human hair 14 to $15 \%, 8 \%$ in horse hair and $3 \%$ in horse's hoof, etc. ${ }^{[59]}$ Keratin contains histidine, lysine, and arginine which are present in the molecular ratios of approximately 1:4:12. Keratin composed of Sulphur, Tyrosine, tryptophane, Phenylalanine, Glycine which are present in very small quantity i.e. approximately 2 to $3 \%$ and $15 \%$ nitrogen. ${ }^{[60]}$

The feather proteins have an amino acid composition in the high proportion of glycine and serine. The amino acid composition of feather keratin showed only minor changes when the proteins were subjected to fractionation, so the feather keratins differ markedly from the mammalian keratins, which can be fractionated into the major families with characteristic compositions and molecular size. The feather keratins were shown many years ago to be homogeneous and to have a low molecular weight. ${ }^{[61][62]}$

\section{Amino acid analysis of chick feather keratin in mol\%}

[SCMK- S (thioglycollate content) carboxyl methyl keratin]

\begin{tabular}{lll}
\hline Residue & Whole rachis & SCMK extract \\
\hline Alanine & 8.7 & 8.6 \\
Arginine & 3.8 & 3.6 \\
Aspartic acid & 5.6 & 3.4 \\
Half cystine & 7.8 & 8.2 \\
Glutamic acid & 6.9 & 6.8 \\
Glycine & 13.7 & 13.9 \\
Histidine & 0.2 & 0 \\
Isoleucine & 3.2 & 3.2 \\
Leucine & 8.3 & 7.8 \\
Lysine & 0.6 & 0.1 \\
Methionine & 0.1 & 0 \\
Phenylalanine & 3.1 & 3.3 \\
Proline & 9.8 & 10.5 \\
Serine & 14.1 & 15 \\
Threonine & 4.1 & 3.9 \\
Tryptophan & 0.7 & 0.7 \\
Tyrosine & 1.4 & 1.2 \\
Valine & 7.8 & 8 \\
\hline PARATION & AND ITS DERIVATIVES
\end{tabular}

- The chicken feathers are first dissolved by using suitable reducing agents and then precipitated protein is collected by using ammonium sulphate solution ${ }^{[6]}$ which can be used to made films, hydrogels, micro particle, nanoparticles for purpose of food, cosmetology, medical, agriculture and other products. ${ }^{[4]}$ 
- Phytokeratin is a composite product made by blending free amino acids from plants in the same proportions as that of found in popular human hair amino acid products. Some phytokeratins are the Hydrolyzed Soy Protein, Hydrolyzed Corn Protein \& Hydrolyzed Wheat Protein. They are used for the Moisturizing, Film-forming and Moisture binding effects. ${ }^{[58]}$

- Keratin was obtained by oxidative extraction yielding keratose powder and further resuspended to form hydrogels and the drugs ciprofloxacin ${ }^{[52]}$ and halofuginone [53] incorporated in this step through the electrostatics interactions.

- Hydrolyzed keratin can be obtained by addition of hydroxyl group in to the structure of keratin protein. Keratin is hydrolyzed by acid, alkali or by using the enzymes to convert it into hydrolyzed keratin. ${ }^{[7]}$

- Hydrogels are formed from keratins obtained by oxidative preparation are called as keratose. ${ }^{[64]}$

Keratin can be processed in various forms, some of which mentioned below. ${ }^{[24]}$

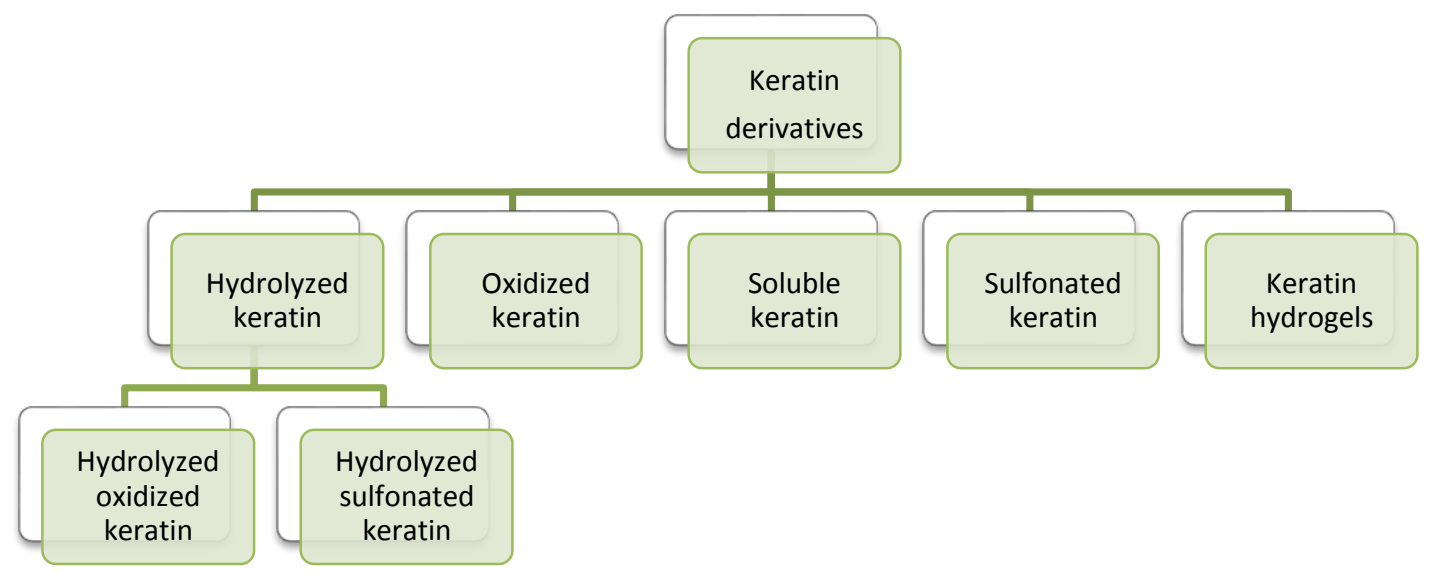

\section{TOXICOLOGICAL STUDIES ON KERATIN PROTEIN}

According to a recent study, hydrolyzed keratin sourced from hoof meal, \& sheep wool was found to be non-irritant, non-mutagenic in an oral study (Rat). ${ }^{[27][28]}$ No dermal irritation and ocular irritation of keratin(5\%) was predicted in rabbit study. ${ }^{[28]-[31]}$ Repeat dose toxicity and carcinogenic effect of keratin had yet not found in any relevant publication.

\section{PHARMACEUTICAL APPLICATIONS}

\section{Nano particles}

The incorporation of drugs into the nanoparticles is best option for increasing the efficiency of the particular drug. According to recent studies keratin based nanoparticles are very effective anticancer drug-carriers possessing a degree of tumor targeting ability. ${ }^{[10][11]}$ This tumor targeting 
ability of nanoparticles is attributed to their $\mathrm{pH}$ sensitivity. ${ }^{[11]}$ Recent research studying of efficient strategy to control and regulate the mucoadhesion and drug release of keratin based nano drug delivery system and the revalation of keratins in different $\mathrm{pH}$ conditions are helpful for the design and development of mucoadhesive drug delivery system. ${ }^{[32]}$

Gold nanoparticles, coated with keratin exhibit antibacterial activity against S. aureus (Bovine Mastitis Bacteria) with biocompatibility. ${ }^{[12]}$ It also possess antioxidant activity. ${ }^{[14][15]}$ Recently, an article reported the development of keratin-g-polyethylene glycol nanoparticles loaded with doxorubicin (DOX) and indicated that the loading efficiency increases with the increase of the keratin content on the keratin-g-PEG nanoparticles due to the formation of hydrogen bonds between keratin and drug. Higher release rates are obtained at intracellular level with efficient internalization showing the promising applications of keratin-g-PEG as drug carriers for cancer therapy ${ }^{[56][1]}$.

Silver nanoparticles coated with keratin act as an anti-cancer agent are shown to have improved stability in aqueous environment. ${ }^{[13]}$ Now a days, there is much progress in treatment of collagen by using keratin-based materials.

\section{Keratin film}

These biomaterials are widely used in pharmaceuticals. Generally biomaterials are integrated into devices or implants and must be compatible with the transplanted body. Some keratin films which prepared by using solvent casting technology are used for production of films having much high quality requirement. ${ }^{[1]}$ Keratin films prepared from numerous hair samples since it is highly sensitive and reproducible. Keratin film is suitable for the efficient screenings of many chemical and natural substances. Keratin obtained from poultry feathers are modified with glycerol, which acts as a plasticizer. The films are "tough" and the mechanical properties show similarities to the properties of commercially available thermoplastics. The keratin films were produced in a few minutes without reducing or oxidizing agents. ${ }^{[40]}$ Keratin films are able to withstand chemical and physical stimulations such as UV, perm, bleach and thermal treatments.

According to recent study on keratin film was found to be used for ocular surface reconstruction as human amniotic membrane very effectively. ${ }^{[17]}$ it was proposed as an alternative carrier and showed to be suitable for corneal epithelial cell expansion. These film based materials can be successfully implanted in to a corneal stromal pocket in vivo. They causes a mild inflammatory response which can be controlled by using low dose of topical steroids. ${ }^{[63]}$

\section{Micro needles}


It improve the patient compliance, transdermal delivery of drug is more convenient and suitable, because it avoids first pass effect and gastric irritation. Keratin micro needles have been successfully used to deliver drugs and other components such as serum, albumin, bovine albumin and calcein suggesting their safety and potential in delivery of drug. ${ }^{[34]}$

\section{Keratin hydrogels}

Recently discovered that keratin hydrogels have homeostatic properties and it have ability to absorb fluid and may be effective hemostat. ${ }^{[19]}$ The keratin gels applied on injury site, by instigating thrombus formation and by forming a seal or mesh like structure on the wound site that acted as a scaffold to allow for granulose tissue formation. ${ }^{[36]}$ The ability for keratin protein-based biomaterials to be translated into the human is elucidating the mechanisms by regulating hemostasis and nerve regeneration. ${ }^{[37][38]}$

These hydrogels are effective polymeric system for tissue engineering as well as regenerative medicine application because it supports the sustained release of therapeutic agents. Some reports are describes the use of hydrogels for sustained release of antibiotics; which is useful for bone regeneration $^{[18]}$ and preventing traumatic injury, acute infections. ${ }^{[64]}$

\section{Keratin based drug delivery system and their sustained \& controlled release actions}

Keratin based biomaterials are capable of providing sustained and controlled release of antibiotics as effectively formulated for inhibition of bacterial growth both in vitro and in vivo. These types of formulations are compatible with mineralized component for a combined treatment modality to inhibit bacterial infection from trauma and battle field injuries and promote bone generation. ${ }^{\text {[33] }}$ The drugs ciprofloxacin ${ }^{[52]}$ and halofuginone ${ }^{[53]}$ incorporated in this step through the electrostatics interactions. Keratin-ciprofloxacin and keratin-halofuginone hydrogels formulation support the sustained release action of the drugs over 3 weeks and 7 days respectively, with pharmacological activity. In a recent study, diclofenac drug was added to keratin solution to prepare drug- keratin films. These were further crosslinked with transglutaminase and the results indicated that diclofenac release is closely related to the solubility of keratin films. ${ }^{[54]}$

The presence of free cysteine residues in keratin sponges allows the immobilization of bioactive agents. Lysozyme was immobilized in a keratin sponge via thioether bonds and disulfide bond. ${ }^{\text {[55] }}$

\section{Other pharmaceutical products}

Keratin used as biomaterials for the preparation of keratin sponges, Scaffolds, Keratin fiber and in Tissue engineering. ${ }^{[16]}$ It can be processed in to various forms, for e.g. micro particles for improving the technology of Drug release action. ${ }^{[22][35]}$ It recently discovered for peripheral nerve repair and wound healing. ${ }^{[20][21]}$ 


\section{COSMETICAL APPLICATION}

Proteins are the basic building blocks for today's skin and hair care products. Proteins are isolated from a variety of sources and possess properties that are essential for the care and protection. According to VCRP (Voluntary Cosmetics Registration Programme) data which analyzed in year 2016, verified that Hydrolyzed keratin was the most reported ingredient in safety assessment of the cosmetic product. ${ }^{[23]}$ There are various approaches to convert the keratin protein in to hydrolyzed keratin. ${ }^{[4]}$

Hydrolyzed keratin acts as a humectant which reduces loss of water from the dermal layer of skin. ${ }^{[26]}$ It is particularly useful for treating hair that has been damaged due to permanent Waving $\&$ Bleaching because it has protective colloid effect which reducing the chapping and irritancy caused by detergents and other harsh products. Hydrolyzed keratin is also very effective moisturizer for the skin. ${ }^{[9]}$

These type of cosmetics products improved elasticity and hydration properties. ${ }^{[25]}$ It has reported maximum concentration of use i.e. up to $5 \%$ used in dressing, hair tonics and other growing pharmaceutical aid. ${ }^{[23]}$

○ Appearance: Clear amber liquid

○ Volatility: $1 \mathrm{gm} / \mathrm{Hr} / 105^{\circ} \mathrm{C}$

○ $\mathrm{pH}: 5.5$ to 7.0

○ Microbial count when packed: 100 O.P.G. max no pathogens. ${ }^{[8]}$

\section{Formulations for hair}

Keratin was able to improve both mechanical and thermal properties of normal hair. It was compatible with water environment supporting its application as a cosmetic product. ${ }^{[41]}$ However, the study of its cytotoxicity and genotoxicity indicated that decreased cell viability and skin irritation. The peptide linkage (which contains mainly cysteine amino acid) was found to be noncytotoxic, and it does not inhibit cell growth nor induce DNA damage or DNA crosslinking in human foreskin. ${ }^{[42]}$

Keratin-based protein has biological evaluation and strengthening properties on relaxed hair. ${ }^{[43]}$ Shampoo containing keratin will strengthen human hair, rebuild damaged hair and keep it from further breakage. ${ }^{[4]}$ Recently discovered straightening cream is used to straighten the kinky, curly, or even wavy hair. There is a number of hair straightening compositions of creams, shampoo and conditioners available today, but a correct composition and methods are needed to produce better and safe formulation. ${ }^{[45]}$ 
Treating wool keratin with urea is generally known to swell the wool fiber to allow permeation of treatment solution beyond the surface cuticle in hair. ${ }^{[51]}$

\section{Keratin Complex Smoothing Therapy}

The recent innovative technology in Smoothing Therapy treatments binds keratin to the hair. This process helps prevent humidity from penetrating the hair, thus locking out frizz. In addition, Keratin Complex Color Therapy incorporates this signature keratin technology into the haircoloring process, which helps to make the hair stronger and smoother as it undergoes a color transformation

\section{In skin care product}

In the long-term study, the beneficial effect of application of wool keratin samples on healthy skin has been demonstrated. Hydrolysed keratin protein derived from wool may be applied alone or combined with wool internal lipids structured improving in both cases the elasticity, hydration and moisture sorption-desorption profile. ${ }^{[48]}$ This new combination of derivatives from wool fiber can be suitable for designing new cosmetic or pharmaceutical products for skin care because internal wool lipids are rich in cholesterol, free fatty acids, cholesterol sulphate and ceramides. ${ }^{[46][47][49]}$

It has an effective moisturizing ability to penetrate down through the top six layers of the epidermis, enhancing the moisture content of the skin, Gives skin a soft, healthy appearance for the skin. ${ }^{[58]}$ As with collagen proteins, it is substantive. Since Hydrolyzed keratin is a primary constituent of skin, it makes good sense to use a protein of this type in skin preparations. Keratin hydrolysate acts as a humectant (it binds water from lower layers of the epidermis to the stratum corneum) as well as an occlusive (it reduces trans-epidermal water loss). Adding keratin hydrolysates to the ointment base did not cause phase separation even after 6 months storage. ${ }^{[50]}$

\section{Keratin based nail cosmetic products}

There is limited source of human nail plate for studying drug permeation, for the treatment of various nail diseases. Keratin can be extracted by using reductive conditions and its films prepared by the method of solvent evaporation. The produced films were suitable for permeation experiments regarding to its water resistant property and mechanical stability. ${ }^{[57]}$

A highly effective daily keratin protein treatment that helps repair damaged nails with the power of keratin protein. Is the RESCUERXX'M DAILY KERATIN TREATMENT product, Keratin Protein is a main component of the natural nail. Solubilized keratin proteins bond to the natural nail to help strengthen the nail plate.

\section{In others cosmetics}


Some of derivatives of keratin may be used in products that can come into contact with the eye or mucous membranes. For example, hydrolyzed keratin is used in mascara at up to $0.2 \%$ and in detergents and bath soaps at up to $0.028 \%$ and also was reported to be used in hair sprays at a maximum concentration of $0.059 \%$. Additionally, some of these derivatives were reported to be used in hair sprays and could possibly be inhaled.

\section{CONCLUSION}

It is concluded that keratin which is obtained from biomass like human hair, nails, animals, horns, claws, hooves, feather, wool, hoof and outer layer of skin and plant such as maize, wheat and rice has vast applications in pharmaceutical industry. As natural keratin is less effective but its processed forms are very effectively used in various fields like preparation of biomaterials, nano particle, different drug delivery systems which having sustained and controlled released actions, multiple pharmaceutical preparations of hydrogels, films and various types of cosmetic products. These animal keratin and phytokeratin can be used very safely on human being. This is one of the major step for the reducing the waste of biomass including plants and animals.

\section{ACKNOWLEDGEMENTS}

This review was partially supported by Ideal College of Pharmacy \& Research Institute, Kalyan. We thank Miss Girija Verma (M.Sc.-Microbiology) for advising and sharing their pearls of wisdom with us during the course of this review. We are immensely grateful to Prof. M. Mirchandani (M. Pharm.) for their comments and moderation on this paper to improve the script significantly, although any errors are our own and should not tarnish the reputations of these esteemed professions.

\section{REFERENCES}

1. Andreia Vasconcelos \& Artur Cavaco-paulo, "The use of Keratin in Biomedical application" current drug targets-2013, 14, 612-619.

2. Pawel Staron, Marcin Banach, Zygmunt KDWASKI, "Keratins- Origins, properties \& applications" CHEMIK-2011, 65, 10, 1019-1026.

3. P. Aramwit, "Introduction to biomaterials for wound healing" Wound healing biomaterials2016.

4. R. Karthikeyan, S. Balaji \& P K Sehgal "Industrial application of keratins- A Review" Journal of Scientific \& Industrial Research Vol. 66, (2007), PP. 710-715.

5. D. Saravanan, "Spider Silk- Structure, properties and spinning." Journal of Textile and Apparel, Technology and Management Vol. 5, Issue 1, winter 2006. 
6. Arun Gupta, Narul Diyanah, Binti Kamarudin, Chua Yeo Gek Kee \& Rosli Bin Mohd. Yunus, "Extraction of keratin protein from chicken feather" David Publication, Eg. 6, (2012) 732-737

7. Swati Sharma, Arun Gupta, "Sustainable management of keratin waste Biomass: Application \& Future Perspective" An International journal of Brazilian Archives of Biology \& Technology vol. 59: e16150684, 2016, ISSN 1678-4324.

8. 11535 Bradley avenue PACOIMA, CA, 91331- Technical Bulletin- Hydrolyzed keratin protein.

9. Wiegmann HD, Kamathyk, Ruestsch SB, Busch P\& Tesmann H, "Characterization of surface deposit on Human hair fibers" JSOC Cosmet Chem, 44 (1990) 387-390.

10. Li, Y: Zhi; X; Lin, J.; You, X. ; Yuan, J. "Preparation \& Characterization of DOX loaded keratin nanoparticles for PH/GSH dual responsive release.” Mater Sci. Eng. C 2017, 73, 189-197.

11. Xu, H, Shi, Z.; Reddy, N.; Yang, Y. "Intrinsically water- stable keratin nanoparticles are there in vivo bio distribution for target delivery." J. Agric. Food chem. 2014, 62, 91459150.

12. Tran, C. D.; Prosenc, F.; franko, M. facile Synthesis, Structure, biocompatibility \& antimicrobial property of gold nanoparticle composites from cellulose \& keratin. J. Colloid Interface Sci. 2018, 510, 237-245.

13. Reichl, S. films based on human hair keratin as substrates for cell culture \& tissue engineering. Biomaterial 2009, 30, 6854-6866.

14. Meignanalakshmi Sundaram, Legadevi R, Afrin Banu N, Gayathri V, Palanisammy A. "A Study on Antibacterial activity of Keratin Nanoparticle from Chicken feather waste against Staphylococcus aureus (Bovine Mastitis Bacteria) \& its antioxidant activity.

15. Sarananan S, Sricharan nethala, Soumiri pattanaik, Anjali tripathi, Ambigapathimoorthi, N. Selvamurugan (2011). "Preparation, Characterization \& anti-microbial activity of a biocomposit Scaffold Containing Chitosan/nano hydroxyapatite/nano silver for bone tissue engineering” International Journal of Biological macromolecule, Vol.49, 188-193.

16. Jillian G. Rouse \& Mark E. Van Dyke, "A Review of Keratin- based Biomaterials for Biomedical applications” ISSN-2010, 3, 999-1014.

17. Reichl S, Borrelli M, Geerling G. "Keratin films for Ocular Surface reconstruction" Biomaterials 2011; 32(13): 3375-86. 
18. Tachibana A, Kaneko S, Tanabe T, et al. "Rapid fabrication of Keratin-hydroxyapatite hybrid Sponges toward Osteoblast Cultivation \& differentiation." Biomaterials 2005; 26(3); 297-302.

19. Aboushwareb T, Eberli D, Ward C, et al. "A keratin biomaterial gel hemostat derived from human hair: Evaluation in a rabbit model of lethal liver injury." J Biomed mater res B 2009; 90(B-1): 45-54.

20. Blanchard CR, Smith RA, Siller-Jackson A. "Keratinous protein material for wound healing application \& method" US patent 6159496, 2000.

21. Sierpinski P, Garrett J, Ma J, et al. "The use of keratin biomaterials derived from human hair for the promotion of rapid regeneration of peripheral nerves." Biomaterials 2008; 29(1): 118-28

22. Dave Jao, Ye Xue, Jethro Medina \& Xiao Hu, "Protein Based Drug delivery materialsReview (2017) MDPI.

23. Chairman, Wilma F. Bergfeld, M.D., F.A.C.P.; Donald V. Belsito, M.D.; Ronald A. Hill, Ph.D.; Curtis D. Klaassen, Ph.D.; Daniel C. Liebler, Ph.D.; James G. Marks, Jr., M.D.; Ronald C. Shank, Ph.D.; Thomas J. Slaga, Ph.D.; and Paul W. Snyder, D.V.M., Ph.D. The CIR Director is Lillian J. Gill, DPA. This safety assessment was prepared by Christina L. Burnett, Scientific Analyst/Writer and Bart Heldreth, Ph.D., Chemist CIR. "Safety Assessment of Keratin and Keratin-Derived Ingredients as Used in Cosmetics" 2016 Cosmetic Ingredient Review.

24. Nikitakis $\mathbf{J}$ and Lange B. International Cosmetic Ingredient Dictionary and Handbook. 16th ed. Washington, DC: Personal Care Products Council, 2016.

25. C. Barba, S. Mender, "Cosmetic effectiveness of topically applied hydrolyzed keratin peptides \& lipids derived from wool” Skin Research \& Technology 2008, 14; 243-248.

26. Pavel Mokrejs, Matous Hutta, "The Cosmetic \& dermatological Potential of keratin Hydrolysate” Journal of Cosmetic Dermatology 2017: 12319.

27. Noda J, Imai T, Kida K, and Otagiri M. The physicochemical and biopharmaceutical properties of fragmented keratin as a new drug carrier. Biol Pham Bull. 1996;19(3):466473.

28. Personal Care Products Council. 1-28-2016. Hydrolyzed Keratin. Unpublished data submitted by Personal Care Products Council.

29. Personal Care Products Council. 2016. Soluble Keratin. Unpublished data submitted by Personal Care Products Council. 
30. Consumer Product Testing Co. 1984. Primary dermal irritation in rabbits; primary ocular irritation in rabbits; acute oral toxicity in rabbits: Hydrolyzed Keratin $(\mathrm{MW} \sim 500 \mathrm{Da})$ Experiment Reference No. 84229-1. Unpublished data submitted by Personal Care Products Council.

31. Food and Drug Research Laboratories, Inc. 1976. Rabbit eye irritation study (20\% Hydrolyzed Keratin from hoof meal). Unpublished data submitted by the Personal Care Products Council.

32. Zhongjun Cheng, Xiaoliang Chen, "Development of keratin nanoparticle for controlled gastric mucoadhesion \& drug release” Journal of Nano-biotechnology (2018) 16:24.

33. Saul, J M, Ellenburg, MD; Van Dyke, ME. "Sustained Release and Bioactivity of Antibiotics from keratin hydrogels." Paper no. 393, 56 ${ }^{\text {th }}$ Annual meeting of the Orthopaedic Research Society.

34. Pierre MBR, Rossetti FC. "Microneedle Based drug delivery system for transdermal route." Current Drug Target 204; 15: 281-291.

35. Ikkai, F.; Naito, S. Dynamic light scattering and circular dichroism studies on heat-induced gelation of hard-keratin protein aqueous solutions. Biomacromolecules 2002, 3, 482-487.

36. Aboushwareb, T.; Eberli, D.; Ward, C.; Broda, C.; Holcomb, J.; Atala, A.; Van Dyke, M. "A Keratin biomaterial gel hemostat derived from human hair: Evaluation in a rabbit model of lethal liver injury." J. Biomed. Mater. Res. B 2009, 90, 45-54.

37. Sierpinski, P.; Garrett, J.; Ma, J.; Apel, P.; Klorig, D.; Smith, T.; Koman, L.A.; Atala, A.; Van Dyke, M. "The use of keratin biomaterials derived from human hair for the promotion of rapid regeneration of peripheral nerves.” Biomaterials 2008, 29, 118-128.

38. Apel, P.J.; Garrett, J.P.; Sierpinski, P.; Ma, J.; Atala, A.; Smith, T.L.; Koman, L.A.; Van Dyke, M.E. "Peripheral nerve regeneration using a keratin-based scaffold: Long-term functional and histological outcomes in a mouse model.” J. Hand Surg. Am. 2008, 33, $1541-1547$.

39. Toshihiro Fujii, "Hair keratin film as a substitute device for human hair - Application in hair care science” J. Biol. Macromol., 12(1), 3-15 (2012)

40. Justin R. Barone, Walter F. Schmidt, Christina F. E. Liebner, "Thermally processed keratin films" Journal of applied polymer science 2005- 21901.

41. Parry, D.A.D., Smith, T.A., Rogers, M.A. and Schweizer, "J. Human hair keratinassociated proteins: sequence regularities and structural implications.” J. Struct. Biol. 155, 361-369 (2006) 
42. Fernandes, M., Gomes, A., Vasconcelos, A., Munteanu, F.-D., Tzanov, T., Gonc salves, M., Guebitz, G.M., Cavaco-Paulo, “A. et al. Protein disulphide isomerase-assisted functionalization of keratin-based matrices.” Appl. Microbiol. Biotechnol. 90, 1311-1321 (2011).

43. M. M. Fernandes*, C. F. Lima, A. Loureiro*,à, A. C. Gomesà and A. Cavaco-Paulo*. "Keratin-based peptide: biological evaluation and strengthening properties on relaxed hair" International Journal of Cosmetic Science, 2012, 34, 338-346.

44. Atikah Bt Mad Nawi. "FORMULATION OF SHAMPOO FROM KERATIN PROTEIN" Faculty of Chemical \& Natural Resources Engineering UNIVERSITI MALAYSIA PAHANG February 2013.

45. Suguna Jeganathan, "FORMULATION OF HAIR STRAIGHTENING CREAM FROM KERATIN PROTEIN.” Faculty of Chemical \& Natural Resources Engineering UNIVERSITI MALAYSIA PAHANG JANUARY 2015.

46. C. Barba1, S. Me'ndez1, A. Roddick-Lanzilotta2, R. Kelly3 , J. L. Parra1 and L. Coderch. "Cosmetic effectiveness of topically applied hydrolysed keratin peptides and lipids derived from wool" Skin Research and Technology 2008; 14: 243-248

47. Coderch L, de la Maza A, Soriano C, Erra P, Parra JL. "Chromatographic characterization of internal polar lipids from wool.” J Am Oil Chem Soc 1995; 72: 1715-1720.

48. Hachiro T, Yuko K, Kunio I, Shoko S, Fumio I, Keiji I, Kohdo Y, Mizuho Y. "Water sorption-desorption test of the skin in vivo for functional assessment of the stratum corneum.” J Invest Dermatol 1982; 78: 425-428.

49. Coderch L, Fonollosa J, Martı' M, Garde F, de la Maza A, Parra JL. "Extraction and analysis of ceramides from internal wool lipids.” J Am Oil Chem Soc 2002; 79: 1-6.

50. Pavel Mokrejs PhD, Matous Hutta MSc, Jana Pavlackova PhD, Pavlina Egner PhD, Lubomir Benicek PhD. "The cosmetic and dermatological potential of keratin hydrolysate" Journal of cosmetics Dermatology 2017.

51. Jeanette M. Cardamone, Alberto Nunez, Rafael A. Garcia, and Mila Aldema-Ramos. "Research Letter- Characterizing Wool Keratin" Hindawi Publishing Corporation Research Letters in Materials Science Volume 2009, Article ID 147175.

52. Saul JM, Ellenburg MD, de Guzman RC, et al. "Keratin hydrogels support the sustained release of bioactive ciprofloxacin.” J Biomed Mater Res A 2011; 98A(4): 544-53.

53. Peyton CC, Keys T, Tomblyn S, et al. "Halofuginone infused keratin hydrogel attenuates adhesions in a rodent cecal abrasion model.” J Surg Res 2012; 178(2): 545-52. 
54. Cui L, Gong J, Fan X, et al. "Transglutaminase-modified wool keratin film and its potential application in tissue engineering." Eng Life Sci 2012.

55. Kurimoto A, Tanabe T, Tachibana A, et al. "Keratin sponge: Immobilization of lysozyme." J Biosci Bioeng 2003; 96(3): 307-9.

56. Li Q, Zhu L, Liu R, et al. "Biological stimuli responsive drug carriers based on keratin for triggerable drug delivery." J Mater Chem 2012; 22: 19964-73.

57. Lusiana, Reichl S, Müller-Goymann CC. "Keratin film made of human hair as a nail plate model for studying drug permeation.” Eur J Pharm Biopharm 2011; 78(3): 432-40.

58. "Phytokeratin TM PF Protein Plant Protein Rejuvenation for Your Hair and Skin.”INCI Name: Hydrolyzed Soy Protein \& Hydrolyzed Corn Protein \& Hydrolyzed Wheat Protein SAP Code\#: 137650, 2014.

59. Buchtala, H.Z.physiol. chem.,85, 241, 246, 355 (1913).

60. RICHARD J. BLOCK “Composition of keratin” January 23, 1939.

61. Keitr Gregg and George E. Rogers "Feather Keratin: Composition, Structure and Biogenesis” Biology of the Integument, pp 666-694, 1986.

62. Arai KM, Takaha shi R, Yokote Y, Akahane K, "Amino acid sequence of feather keratin from fowl” Eur J Biochem 132: 501-507,1983.

63. Nadine joepen, Maria Borelli, Yaqing feng, "Keratin Films in Ocular Surface Reconstruction: Biocompatibility Experiments” iovs journals, vol.54, 3900, June 2013.

64. Justin M. Saul, Mary D. Ellenburg, "Keratin hydrogels support the sustained release of bioactive ciprofloxacin” Journal of Biomedical Materials Research Part A / Volume 98A, June 2011.

\section{AJPTR is}

- Peer-reviewed

- bimonthly

- Rapid publication

Submit your manuscript at: editor@ajptr.com

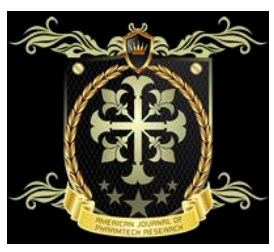

